\title{
Neurosurgical credentials: a history and critique
}

\section{Sidney Tolchin, M.D.}

\section{La Mesa, California}

The author presents a review of the process of peer evaluation in this century, as well as how certification and techniques of evaluation in the practice of medicine and neurosurgery have evolved. The effect of licensure on the workforce, the influence of trade laws on quality of education and training, and the new paradigm of competition and managed medical practices have made a remarkable impact on the nature of the care of patients in the United States. The author also discusses the effect of risk management and litigation on the quality of medical care, the nature of outcomes evaluation and economic credentials in the absence of appropriate instruments for such evaluation, and alternatives for the future of the credentials process.

\section{Key Words * credentials * certification * licensure * managed care * risk management * outcomes * recertification}

At the turn of the last century the practice of medicine in the United States was, at best, inconsistent in quality. Concerned about the care of the population, Nathan Davis, a New York State physician, envisioned and organized, in 1847, the American Medical Association (AMA), with Nathaniel Chapman as its first president. The 222 original delegates adopted the first national standards for medical education, establishing prerequisites for the study of medicine. The politics of that time militated against control of medical schools by any single group. Naturopaths and homeopaths dominated American medicine. The German system of hospital-based medicine, allopathy, depended on treatment of manifestation of the disease with medications, surgery and nursing care. Homeopathy depended on the administration of small aliquots of drugs, the actions of which in large amounts caused symptoms similar to those associated with the disease. Naturopathic treatment depended primarily on the use of herbs and other earth-based substances that had been observed historically to alleviate the symptoms of disease. The interaction of these methods of treatment led to a hodgepodge of unscientific services, with no controls and no satisfactory evaluation of outcomes. The AMA efforts in developing standards were fruitless, and the organization wallowed in its own lack of respectability. In 1898, William Simmons, who possessed two fraudulent medical degrees,[7] took control of the organization. The industry of medicine, however, was recognized by entrepreneurs as being important, established, and profitable.

The Association of American Medical Colleges (AAMC) had its first meeting in 1894. In 1903, it attempted to establish medical accreditation programs. Representing the interests of medical colleges, it too was unsuccessful in implementing major changes.

The industrialist millionaire John D. Rockefeller decided to enlist the support of his Carnegie Foundation to impose some control over the medical community and commissioned Abraham L. Flexner to research and produce a document describing the then-current state of medicine. The 1910 Flexner Report,[3] encompassing 40 states and 163 medical schools, brutally criticized clinical training in U.S. medical schools, especially compared with the medical training available in Europe. Flexner believed that the curriculum was rooted in the disciplines of medicine but that it was not restrained by evidence, evaluation, and outcome measures. He criticized the apprentice program for not providing a background of science but instead emphasizing practice itself, and he noted that there was no consistency in training. Flexner wrote, "The story of medical education in [this] country is not the story of complete success. We have made ourselves the jest of scientists through out the world by our lack of a uniform standard." Furthermore, "No one can read these figures without admitting that the situation is deplorable, and that the vast majority of our schools are not prepared to give the proper clinical instruction. . . . Moreover, . . . restriction in [available patients] . . greatly hampers the development of the professor and his assistants by the absence of suggestive problems and his inability to subject his own ideas to the test of experience."[3] He continued, "Of the eleven medical schools now existing in the state [New York], only the bona fide university departments can then expect to survive: outside of New York city, Syracuse University alone has just now a chance. The schools of Buffalo, Albany, and Brooklyn belong to the past. None of the three has even yet emerged from the fee-dividing stage. Syracuse, with a smaller total fee income than any of them, devotes every dollar to the development of the fundamental branches and has fairly earned support from outside."[3] 
Flexner's report became a document of policy and has contributed to the remarkable change in American medicine since that time. That change, the importance of which was rivaled only by the discovery and use of anesthesia and antibiotics, was marked by the closure of many medical schools and the introduction of new teaching methods in those remaining institutions.

In 1927, following implementation of the Flexner Report recommendations, preliminary evaluation of prospective medical school applicants started. Over the next three decades a Medical College Application System, including the Medical College Aptitude Test and, later, a National Resident Matching Program, was instituted. A clinically integrated problem-based learning curriculum was instituted and, over the next 50 years, it became difficult to distinguish one medical school from another as a result of the consistency imparted by adherence to those recommendations.[9]

Following the algorithm of consistency in training, specialty societies established requirements for training to satisfy admission prerequisites. In 1917 the first organization to form a specialty board was a group of ophthalmologists. Training parameters and means of evaluation were designed, which included not only testing measures but also scrutiny of training programs and their directors. In 1933, the Advisory Board for Medical Specialties was formed.[1] This, the precursor to the American Board of Medical Specialties (ABMS), was composed of leaders of multiple specialties.[1] The neurosurgical community, galvanized by Harvey Cushing, formalized the specialty between 1918 and 1930, initially organizing the Society of Neurological Surgery and later, in 1932, the Harvey Cushing Society, which became the American Association of Neurological Surgeons. Neurosurgery was added to the ABMS in 1940. The earliest attempts at ensuring adequacy of training and testing measures were instituted at that time and have evolved into a system that is consistent, fair, and respected by the entire medical community.

The AAMC, the ABMS, and the AMA now comprise the foundation of American medical education. "The AAMC represents all of the nation's 125 accredited medical schools, approximately 400 major teaching hospitals, including 75 Veterans Affairs medical centers, the faculty of these institutions through 89 constituent academic society members, and the more than 160,000 men and women in medical education as students and residents" (see http://www.aamc.org). The ABMS designates and represents the 24 member boards including the American Board of Neurological Surgery (ABNS).[12] The AMA, with its component state medical associations, has centered its activities on preserving the profession of medicine through its socioeconomic activities. It has relinquished a significant degree of leadership in educational, academic, and peer-evaluation activities in its attempts to lead and represent the many components of the complex medical industry as a whole.

The evaluation and accreditation body for graduate medical education, the Accreditation Council for Graduate Medical Education (ACGME), is jointly sponsored by the AMA, the AAMC, the ABMS, the Council of Medical Specialty Societies, and the American Hospital Association. Graduate medical education includes programs that provide preliminary and residency training in medical specialties and subspecialties. The ACGME establishes general procedures for reviewing, developing, and maintaining records on each graduate medical education program and is responsible for informing the program director and other designated parties of the action taken by the reviewing bodies (see http://www.acgme.org). Integral to the ACGME, and the action arm of that organization, are the Residency Review Committees. Selected by the individual specialty boards and, in the case of the ABNS, the AMA and the American College of Surgeons, these committees are responsible for review and approval of the training programs, recommendations for corrective actions, and the imposition of sanctions; they report directly to the ACGME and, although represented by the specialty boards, are not accountable to them. The ABNS does not accredit training programs.

The specialty boards, such as the ABNS, are responsible for development of the general and program requirements for each training program. Approved by the ACGME and, ultimately, the ABMS, the specialty boards also define the specialty and its scope. These individual specialty boards are responsible for tracking the training of each applicant for specialty certification as well as for determining the qualifications of that applicant including local peer review and investigation of practice data. They formulate and implement the written and oral examination segments of the certification process. Although varying somewhat from specialty to specialty, the policies for conferring diplomate status on an applicant are the responsibility of these boards. Appointments to the ABNS are made by the American Association of Neurological Surgeons, the Society of Neurological Surgeons, the American College of Surgeons, the Congress of Neurological Surgeons, the American Academy of Neurological Surgeons, and the Neurosurgical Society of America. (A complete review of the nature and functions of the ABNS may be viewed at http://www.abns.org/.) Certification for diplomate status through the ABMS mechanism therefore implies the involvement of multiple organizations and a system of careful checks and balances integrating the influence of general medicine and surgery, educators, practitioners, hospital administrators, and government.

Such certification, however, is not necessary for one to be designated a specialist, even in neurosurgery. Most states have no specialty requirements, conferring the designation "Physician and Surgeon" to the licensee who fulfills the requirements of the medical boards in those states for general practice. Self-designation can be accomplished, therefore, by listing oneself as such on a name plate, placard, or by advertising in a medium such as the Yellow Pages. Groups of specialists, so designated, can join to 
form "alternative boards" to those of the ABMS. Membership in the ABMS is not mandatory for specialty recognition by certain states. Although some of these "certifying boards" incorporate testing measures and review of training, they have not demonstrated the program review and quality control integral to the process of the ABMS.

There is no defined beginning or end to the credentialing process. The basic equipment may include inheritance of peculiar genetic coding. Avoidance of physical or degenerative neurological disorder and death have obvious influence. Admission to a good college or university requires adequate credentials from a primary education institution and satisfactory scores on college admission tests. Completion of undergraduate basic education does not guarantee adequate performance on medical college aptitude testing. The applicant's college or university diploma must be accompanied by higher-than-average credentials prior to acceptance for medical training. Competition throughout these processes is moderated by collegiality and the inescapable exigencies of the process of life itself, its stresses and pleasures, all contributing to the credentials of personality and motivation measured as well by society. The rather recent requirement of choosing a specialty during the 3rd year of medical school, imposes a difficult dilemma with little or no opportunity for experience to influence such a decision. Competition within the matching program for residency training, especially in neurosurgery, demands the highest credentials during the first years of medical education. Neurosurgery continues to attract the brightest applicants for residency training.

Basic clinical skills-training, including at least 6 months of surgery and not more than 6 weeks of neurosurgery at an accredited ACGME training program, is required prior to starting the neurosurgical program. After that, 5 years of training in the neurological sciences, including at least 3 years of clinical neurosurgery, a minimum of 3 months in clinical neurology, and 1 year as senior resident with primary responsibility for patient management, constitutes the minimum training necessary for approval to sit for the oral board examination. Most candidates receive additional training through enfolded specialty attention or elective training. No neurosurgical fellowships in spine, intracranial, or cerebrovascular surgery are accredited by the ABNS. The Residency Review Committee is considering the evaluation of postgraduate or enfolded programs in the near future.

In spite of the influence of Flexner, the ACGME, AMA, and ABMS on establishing consistency, a gaussian distribution exists when the quality of training programs are judged under the bell curve.[13] The general and program requirements are fulfilled in varying degrees: one program excelling in cerebrovascular disorders, another in spine, still another in the management of epilepsy. The review process for training programs demands satisfactory general training in all aspects of neurosurgery and exposure to all facets of neurological disorder. Ranging from 6 to 9 years, neurosurgical training incorporates laboratory and research experience and opportunities for elective specialty experience. Patient volume and exposure, attending neurosurgeons with focused interests, economically driven availability of advanced technology, and quality of other institutional specialties all contribute to the eventual compendium of individual neurosurgical training. That experience and environment contribute to the credentials of expertise and excellence.

In addition to the recommendation of the training program director, a passing grade on the neurosurgical written examination is now required to document the completion of a residency training program. The ABNS is deliberating the possibility of time-limited provisional recognition of certification immediately following completion of a recognized and approved training program; such provisional status would be removed after approval of practice data and references and a passing grade on oral examination.

A small percentage of practicing neurosurgeons have not obtained board certification, a few having no desire to do so (for whatever reason) and others never having passed their examinations. Litigation and managed care, as well as major hospital and group credentials processes, might influence this number even further in the near future. No state at this time limits the practice of neurological surgery to board-certified practitioners. Several states accept "alternative board" certification. This enigma of practice without board certification produces disturbing influence on the issue of recertification: the question of recertifying someone who was not initially certified has not been satisfactorily resolved. The ABNS recognized the intensive tracking process leading to initial board certification, questioned the validity of written or oral knowledge-based testing procedures, and was the last of the 24 specialty boards to impose time-limited initial certification and a process of recertification. Because of the influence of governmental prerogatives and managed care requirements, this credentialing process will take effect within the next 3 years. The experience and history of such recertification processes used by other specialty boards reveals a pass rate of $94.3 \% \cdot[4,5,8,14]$

In the same year as the formation of the ABNS, the Advisory Board for Medical Specialties stated, ". . as the certifying boards become better established and as they complete the examination of a large group of physicians already practicing specialties, they may find it desirable to issue certificates that are valid for a stated period only."[5] This came only 8 years after the AAMC announced that "The time may come when every physician may be required in the public interest to take continuation courses to ensure that his practice will be kept abreast of current methods of diagnosis, treatment and prevention."[14] In 1969, the American Board of Family Practice was formed and included time-limited certification after appropriate review of training and experience. This limit of 6 years required recertification at or near the end of that time. The first subspecialty recertification 
policy approved by the ABMS was that of pediatric surgery in 1981.

In 1984, the ABMS asked that the member boards consider reaffirming the concepts of recertification for intrinsic reasons apart from threat of legislative or licensing requirements. The ABNS, in company with three other specialty boards, considered those intrinsic reasons and, particularly because of the extended training requirement and the relatively short practice years in comparison to most other specialties, elected not to institute recertification. Recent mounting requests by diplomates resulting from economic credentialing and managed care as well as statutory and state licensing requirements resulted in the decision by the ABNS to institute recertification following time-limited issuance of initial certification. Although not established, the projected 10-year recertification process will most likely require a single reevaluation process in the career of most neurosurgeons unless more frequent recertification requests are received. A surgeon's knowledge base will have deteriorated 3 years after completion of residency training, primarily because of increased focus of practice and lack of use of general knowledge imparted throughout the training process. After 7 years, even further diminution in general knowledge of the neurosciences and basic sciences is recognized. However, the experience, judgment, and technical ability acquired during these times is known to improve substantially. Although a written, and perhaps oral, examination including basic science and general neuroscience will almost certainly be a part of this recertification, the real task of the ABNS will be to define safety and competence, the definitions of which have been elusive in the past half-century. The credentials process in recertification should also include evaluation of outcomes, as originally envisioned by Flexner. Peer review, litigation experience, and health have also been included in the overall recertification and review process. A decided benefit of recertification will be the incentive for all practitioners to review current literature and texts and to attend didactic and technical courses, habits which the majority of neurosurgeons have demonstrated throughout their careers without the need for such incentive.

No matter the accumulation of laurels, whether magna cum laude or alpha omega alpha, Podunk Medical College or University of the World, the eventual review process for interpreting credentials will rest with the local hospital credentials committee. With the landmark College Park Hospital decision, the ultimate responsibility for the acts of medical staff rests with the governing hospital board, through the theory of agency. Although this does not alleviate the responsibility of the practitioner in medical liability, tort or criminal acts, the theory accords the hospital--the primary arena of neurosurgical activity--the authority to govern the activities of its medical staff.

With the advent of the Internet and rapid communication capability, public investigation of a neurosurgeon's credentials has become commonplace. Marketing of services is now a recognized part of the practice of neurosurgery. However, nowhere is the need for adequate credentials so apparent as in the courtroom, where the complete unveiling of the only measures of competency available through evaluation of training, history of experience, participation in continuing medical education, and membership in professional associations takes place. When placed in the adversarial position of defense, a neurosurgeon must demonstrate recent education in technical and scientific matters. Any negative facet of practice in the form of sanctions or limitations imposed by medical staff or state agencies affects the credentials review perceived by judge or jury. A curriculum vitae that encompasses the entire training career of a neurosurgeon is an invaluable tool in the judicial arena.

Society equates these credentials with competency. Previously considered superficial, "bedside manner" and peer relationships, careful documentation and attention to detail, and communication about advance directives and informed consent are all now strong indicators in evaluation of competency. Therefore, these learned, acquired, or endowed characteristics and risk management capabilities are certainly part of one's credentials.

Another facet integral to credentials is the surgeon's recognition of economics in this era. Appreciation of cost in the care and management of patients as well as efficient use of technology are now paramount and have gained alarming importance in the economic credentialing of neurosurgeons.[10,11] The advocacy of the managed care tenets at the expense of patient advocacy to continue to provide care at all has created a paradox for physicians. Suspicion, caution, and aggressive self-interest instilled in the patient by managed care and entrepreneurial medicine have displaced rapport with the physician. The physician's need to maintain a supportive volume of patient contact may be at odds with the time needed to communicate and establish patient confidence and trust, those connections with patients that are so necessary in the treatment of disorders of body or mind. Flexner's lament about the need for volume of patients to inspire excellence has come back to haunt us.

This volume is impacted by many issues. The scope of practice of lesser-trained providers has expanded. Nurse practitioners, chiropractors, and naturopaths are recognized by third-party payers in spite of their lack of credentials and notwithstanding evidence-based studies that confirm that the best is still the cheapest. Turf issues are constantly debated at the ABMS level. The scope of practice of other respected specialties has overlapped carefully guarded and decades-old parochially protected neurosurgical procedures. This has occurred primarily because of a marked increase in the number of medical care providers. A direct result of the Lyndon Johnson Great Society program, the marked increase in residency training programs and physicians, hospitals, and federal funding programs has led to a competitive environment that has nurtured the concepts of managed care, 
rationing of services and technology, loss of collegiality, and disruption of patient-doctor relationships. However, when compared with other specialties, neurosurgery has had a remarkably stable workforce component (Table 1; Figs. 1 and 2).

\begin{tabular}{|c|c|c|c|c|c|c|c|c|c|c|c|c|c|c|c|c|c|c|}
\hline \multicolumn{19}{|c|}{ TABLE 1} \\
\hline $\begin{array}{l}\text { American } \\
\text { Board of }\end{array}$ & 1980 & 1981 & 1982 & 1983 & 1984 & 1985 & 1986 & 1987 & 1988 & 1989 & 1990 & 1991 & 1992 & 1993 & 1994 & 1995 & 1996 & Total \\
\hline $\begin{array}{l}\text { Colon \& Rec- } \\
\text { tal Surgery } \\
\text { Neurological }\end{array}$ & 38 & - & 39 & 31 & 39 & 42 & 45 & 30 & 36 & 48 & 51 & 41 & 62 & 41 & 45 & 44 & 50 & 682 \\
\hline $\begin{array}{c}\text { Surgery } \\
\text { Otstetrics \& }\end{array}$ & 138 & 101 & 151 & 108 & 116 & 118 & 83 & 79 & 76 & 107 & 104 & 118 & 112 & 134 & 100 & 124 & 124 & 1893 \\
\hline $\begin{array}{l}\text { Gynecology } \\
\text { Ophthal mology } \\
\text { Otho paedic }\end{array}$ & $\begin{array}{l}780 \\
496\end{array}$ & $\begin{array}{r}1168 \\
490\end{array}$ & $\begin{array}{l}891 \\
501\end{array}$ & $\begin{array}{l}927 \\
481\end{array}$ & $\begin{array}{l}994 \\
237\end{array}$ & $\begin{array}{r}1193 \\
508\end{array}$ & $\begin{array}{l}596 \\
480\end{array}$ & $\begin{array}{r}1473 \\
508\end{array}$ & $\begin{array}{r}1097 \\
494\end{array}$ & $\begin{array}{r}1035 \\
516\end{array}$ & $\begin{array}{r}1090 \\
532\end{array}$ & $\begin{array}{r}1049 \\
854\end{array}$ & $\begin{array}{r}1148 \\
500\end{array}$ & $\begin{array}{r}1015 \\
288\end{array}$ & $\begin{array}{r}1177 \\
509\end{array}$ & $\begin{array}{r}1136 \\
492\end{array}$ & $\begin{array}{r}1193 \\
492\end{array}$ & $\begin{array}{r}17,962 \\
8378\end{array}$ \\
\hline $\begin{array}{l}\text { Surgery } \\
\text { Otolar yngology } \\
\text { Plastic Surgery } \\
\text { Surgery }\end{array}$ & $\begin{array}{r}570 \\
121 \\
155 \\
1081\end{array}$ & $\begin{array}{l}527 \\
298 \\
199 \\
977\end{array}$ & $\begin{array}{l}319 \\
254 \\
142 \\
897\end{array}$ & $\begin{array}{l}299 \\
255 \\
163 \\
911\end{array}$ & $\begin{array}{l}504 \\
223 \\
185 \\
933\end{array}$ & $\begin{array}{r}465 \\
261 \\
150 \\
824\end{array}$ & $\begin{array}{l}629 \\
251 \\
176 \\
912\end{array}$ & $\begin{array}{r}445 \\
315 \\
115 \\
1001\end{array}$ & $\begin{array}{l}582 \\
303 \\
133 \\
989\end{array}$ & $\begin{array}{l}707 \\
304 \\
158 \\
967\end{array}$ & $\begin{array}{r}664 \\
299 \\
167 \\
1028\end{array}$ & $\begin{array}{r}605 \\
51 \\
180 \\
983\end{array}$ & $\begin{array}{l}652 \\
265 \\
172 \\
898\end{array}$ & $\begin{array}{l}610 \\
271 \\
265 \\
999\end{array}$ & $\begin{array}{l}647 \\
297 \\
209 \\
979\end{array}$ & $\begin{array}{r}679 \\
294 \\
200 \\
1002\end{array}$ & $\begin{array}{l}662 \\
296 \\
194 \\
997\end{array}$ & $\begin{array}{r}9566 \\
4358 \\
2963 \\
16,378\end{array}$ \\
\hline Thoradic & & & & & & & & & & & & & & & & & & \\
\hline $\begin{array}{l}\text { Surgery } \\
\text { Urology } \\
\text { total }\end{array}$ & $\begin{array}{r}110 \\
332 \\
3821\end{array}$ & $\begin{array}{r}131 \\
309 \\
4200\end{array}$ & $\begin{array}{r}159 \\
280 \\
3633\end{array}$ & $\begin{array}{r}136 \\
254 \\
3565\end{array}$ & $\begin{array}{r}135 \\
273 \\
3639\end{array}$ & $\begin{array}{r}120 \\
245 \\
3926\end{array}$ & $\begin{array}{r}147 \\
237 \\
3556\end{array}$ & $\begin{array}{r}141 \\
245 \\
4352\end{array}$ & $\begin{array}{r}136 \\
238 \\
4084\end{array}$ & $\begin{array}{r}159 \\
224 \\
4225\end{array}$ & $\begin{array}{r}122 \\
251 \\
4308\end{array}$ & $\begin{array}{r}122 \\
209 \\
4212\end{array}$ & $\begin{array}{r}142 \\
231 \\
4182\end{array}$ & $\begin{array}{r}141 \\
231 \\
3995\end{array}$ & $\begin{array}{r}156 \\
263 \\
4382\end{array}$ & $\begin{array}{r}159 \\
258 \\
4388\end{array}$ & $\begin{array}{r}160 \\
252 \\
4420\end{array}$ & $\begin{array}{r}2376 \\
4332 \\
68,888\end{array}$ \\
\hline
\end{tabular}

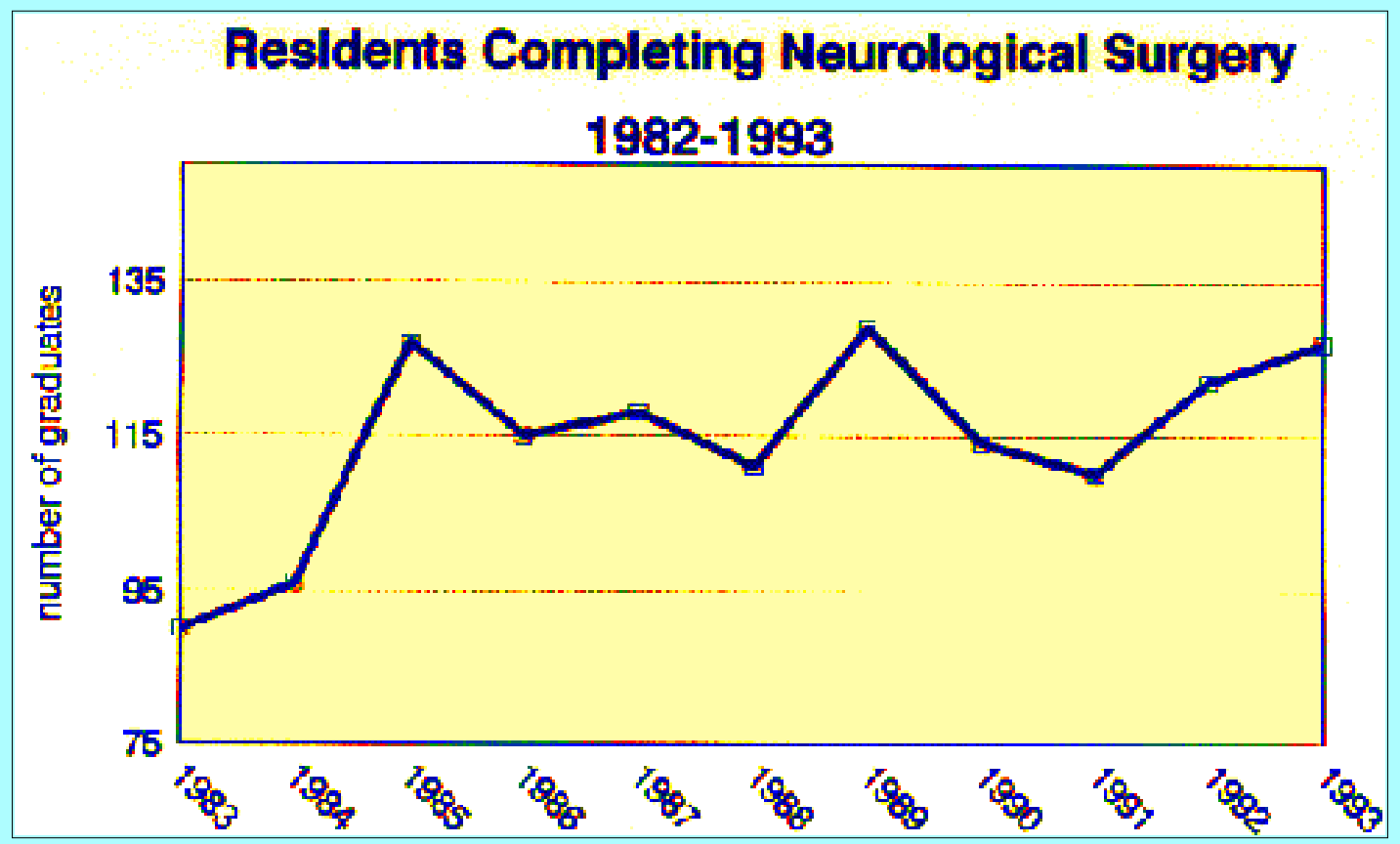

Fig. 1. Chart depicting the number of neurosurgical residents completing their training between 1988 and 1993. (The years listed on the horizontal bar indicate the academic year of completion.) 


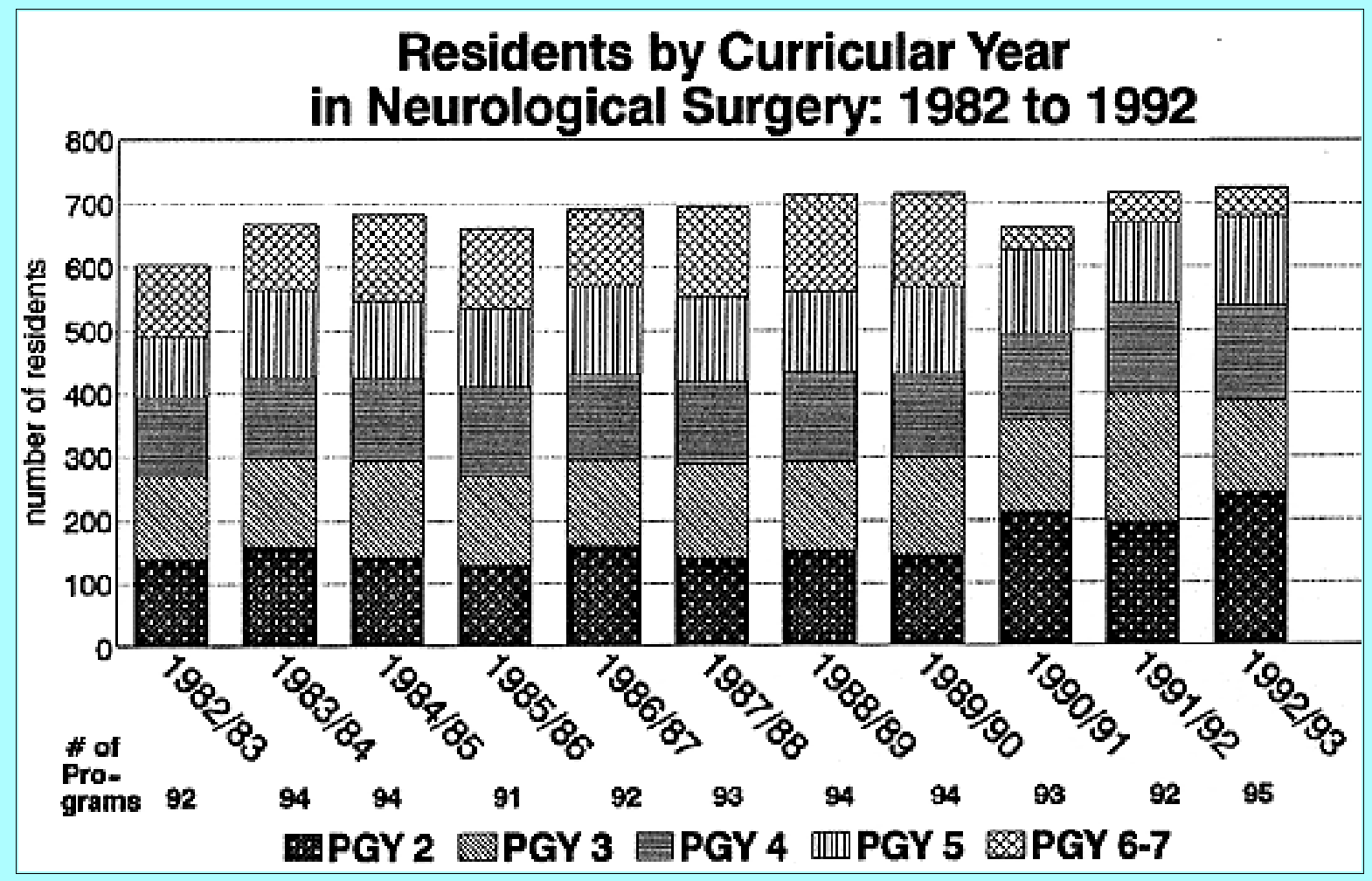

Fig. 2. Bar graph illustrating the number of neurosurgical residents by academic year between 1982/1983 and 1992/1993. Courtesy of the American Board of Neurological Surgery.

The establishment of rigorous training requirements, the prerequesite of excellence for acceptance to training, and the many years required for receipt of credentials in neurosurgery have combined to create and maintain such a stable condition.[2] Debate rages as to what is best for society and best for neurosurgery as a specialty: to render more rigorous the credentials process with its attending diminution in interested applicants to preserve adequate numbers of esoteric technical procedures for the maintenance of expertise, or to reduce the requirements, thus attracting more numbers to the neurosurgical workforce so as to protect our procedures and expand the neurosurgical environment into areas previously of little interest to trained neurosurgeons and currently under the aegis of other specialties.

A troublesome factor in the accreditation of training programs is that of litigation and Federal Trade Commission regulations. A university with a handsome endowment can ill afford to lose such a specialty training program as neurosurgery. The Federal Trade Commission and Justice Department have maintained an almost adversarial position towards the ACGME and residency review committees. Licensure, certification, and other quality measures are often construed by the political arm as methods to limit competition or as tools of monopoly. Using those theories, such a university whose neurosurgical program has been withdrawn from accreditation by the actions of the ACGME can obtain the services and counsel of excellent lawyers in order to overturn such action. The ABMS, ACGME, and residency review committees have no such financial backing to afford the litigation involved in such cases. Long periods of probation and repeated warnings for those very few institutions are of little merit in maintaining quality of training. Unless legislation is forthcoming to protect these accreditation institutions, there is little hope for withdrawal of accreditation when quality and safety are deemed unsatisfactory.

Credentials evaluation, including licensure, certification, recertification, documentation of continuing medical education, proof of recent training for performance of procedures (old or new), health, and behavior, is now within the purview of medical staff or administrative review committees. Most states and hospitals require confirmation of continuing medical education for renewal of licensure.

For many years the achievement of board certification carried no tangible benefit. The sense of fulfillment, pride of accomplishment, and reaching a goal were rewards enough. Today, such certification is required for economic stability and the privilege of practicing neurosurgery. That possession of credentials and continued motivation toward attaining further expertise, with its accompanying recognition, is now associated with financial reward should not denigrate its importance. Neurosurgery has not yet equated such credentials as certification with quality; its intent has only been to confirm completion of training, evaluation and critique of experience, and documentation of ability to pass written and oral examination. Such a definition of quality must remain in local evaluation, patient preference, and outcomes.[6] Until adequate instruments for the evaluation of outcomes are available and proved, current credentials must suffice. 


\section{References}

1. American Board of Medical Specialties: Annual Report and Reference Handbook 1995. Evanston, Ill: American Board of Medical Specialities, 1995, pp 135-137

2. Drake CG: Neurosurgery: considerations for strength and quality. The 1978 AANS presidential address. J Neurosurg 49:483-501, 1978

3. Flexner A: Medical Education in the United States and Canada: A Report to the Carnegie Foundation for the Advancement of Teaching. Washington, DC: Science and Health Publications, 1910, pp 171, 207, 276

4. Lewis RP: Recertification--its time has come. J Am Coll Cardiol 28:260-262, 1996

5. Lloyd JS, Langsley DG: Recertification for Medical Specialists. Evanston, Ill: American Board of Medical Specialties, 1987

6. Long DM: Assurance of competency in residency training: neurosurgical education in the twenty-first century, in Bean JR (ed): Neurosurgery in Transition. Concepts in Neurosurgery, Vol 9. Baltimore: Williams \& Wilkins, 1998, pp 147-156

7. Mullins E, Valentine T: An interview with Eustace Mullins. Interviewed by Tom Valentine. The Spotlight, October $28,1994$. URL: http://www.livelinks.com/sumeria/politics/eustace.html

8. Newble D, Jolly B, Wakeford RE: The Certification and Recertification of Doctors: Issues in the Assessment of Clinical Competence. New York: Cambridge University Press, 1994

9. Patel VL, Kaufman DR, Arocha JF: Cognition and Medical Education: a Critical Appraisal. McGill University Center for Medical Education Web Site.

http://mystic.biomed.mcgill.ca/MedinfHome/DEANBOOK/public_html/FACULTY?MEDICAL-EDUCATION/patel-paper.html

10. Popp AJ: Neurosurgical residency training programs and the workforce debate. AANS Bulletin, Spring, 1996, pp 22-27

11. Popp AJ: The neurosurgical workforce: market effects, public policy, and professional constraints, in Bean JR (ed):

Neurosurgery in Transition. Concepts in Neurosurgery, Vol 9. Baltimore: Williams \& Wilkins, 1998, pp 112-131

12. Seward WF: Trends in specialty certification. Bull Am Coll Surg 35:13-17, 1997

13. Takeuchi JS, Smith NM, Mortimer AM: Medical Education and Societal Needs: A Planning Report for Health

Professionals. Publication No. IOM-83-02. Washington, DC: National Academy Press, 1983, pp 107-147

14. Tolchin S, Bean JR: Board certification: purposes, issues, dilemma, and the future in neurosurgery, in Bean JR (ed):

Neurosurgery in Transition. Concepts in Neurosurgery, Vol 9. Baltimore: Williams \& Wilkins, 1998, pp 171-178

Manuscript received June 27, 1998.

Accepted in final form July 10, 1998.

Address reprint requests to: Sidney Tolchin, M.D., P.O. Box 2665, La Mesa, California 91942. email: sidtolchin@4dcomm.com. 